\title{
Cryptosonorants and the misapplication of voicing assimilation in Biaspectual Phonology*
}

\author{
Sylvia Blaho AND PATRiK Bye \\ CASTL, University of Troms $\varnothing$
}

\section{Introduction}

Biaspectual Phonology (Bye 2005) is an approach to phonological opacity based on a notion of phonology that has been around for a long time: that phonology mediates between systematic/lexical and discrete phonetic representations (Process Morphophonemics; Postal 1968, Kiparsky 1973). In this paper we apply biaspectual phonology to describing the behaviour of cryptosegments, segments whose phonological behaviour is inconsistent with their phonetic realisation. Specifically we'll look at Czech cryptosonorants, which pattern like sonorants phonologically but are obstruents phonetically. ${ }^{1}$ On the assumption that their surface obstruenthood is phonologically encoded, this may be described in rule-based terms by specifying the cryptosonorant underlyingly as [+sonorant] and allowing any rules whose application crucially relies on this sonorant status to apply before the late rule that changes [+sonorant] to [-sonorant]. This style of interaction is of course phonological opacity.

\footnotetext{
*We'd like to thank Vera Procházková for the Czech data. We are grateful to the audiences of BLS31 as well as the 13th Manchester Phonology Meeting for feedback and comments. In particular we'd like to thank Ricardo Bermúdez-Otero, Aliki Evangelopoulou, Suzanne van der Feest, Bruce Hayes, Paula Fikkert, Dafna Graf, Patrick Honeybone, Martin Krämer, Ove Lorentz, Bruce Morén, Marc van Oostendorp, Joe Pater, Curt Rice, Norval Smith, Michal Starke, Nina Topintzi, Peter Svenonius and Jochen Trommer for comments on various aspects of the paper, and the Faculty of Humanities of the University of Troms $\varnothing$ for financial support.

${ }^{1}$ The term cryptosonorant is due, we believe, to Tuttle (2005).
} 
Sylvia Blaho and Patrik Bye

\section{Cryptosonorants in Czech}

\subsection{The General Pattern of Voicing Assimilation}

In Czech a sequence of consecutive obstruents must agree in voicing. ${ }^{2}$ As shown in (1) and (2), assimilation takes place regressively both within and across words. ${ }^{3}$

(1) Regressive voicing assimilation (within the word)

predek 'ancestor' pretka 'GEN.SG'

prosit 'to beg' prozba 'request NOM.SG'

(2) Regressive voicing assimilation (across a word boundary)

/s bisdou/ $\rightarrow$ [zbisdou $]$ 'with poverty'

$/$ nad tebou/ $\rightarrow$ [nattebou ] 'above you'

The pattern can be modelled using a version of Autosegmental Span Theory (McCarthy 2004) with the constraints in (3) to (5). ${ }^{4}$

(3) ObSPAn: A sequence of consecutive [-son] segments form a span on the [voice] tier.

(4) OBSPANHD-R: Every span is right-headed.

(5) SPHD-ID[voi]: For all $x, x$ is the head of a span, $x$ is faithful to its input specification for [voice].

As shown in the tableaux in (6), the winning candidates (b) are the ones in which all of the above constraints are satisfied.

\section{2. $\quad \check{r}$ : The Opaque Bidirectional Pattern}

Czech has two alveolar trills, $r$ and $\check{r}$. According to Dankovičová (1999), the difference between the two trills is primarily one of manner. The plain trill has ' $1-3$ periods of vibration', while the fricative trill will generally add 1 or 2 more. She adds that, for $\check{r}$, 'the constriction is narrower and the velocity of air greater', a clear indication of its obstruenthood. Ladefoged and Maddieson (1996), citing Short (1987), add that $\check{r}$ is post-alveolar. Nevertheless, the behaviour of $\check{r}$ differs from the pattern for other obstruents described above. Within the word, $\check{r}$ always assimilates to

\footnotetext{
${ }^{2}$ We refer to the standard (Prague) dialect. Data is from Hall (2003) and Věra Procházková (p.c.).

${ }^{3}$ In the examples the source of the laryngeal feature is shown in bold. The assimilation target is underlined.

${ }^{4}$ We use binary features, and assume no underspecification in this paper, although given an appropriate formulation of featural faithfulness, our analysis can easily be translated into one using unary features.
} 
(6) Regressive voicing assimilation (canonical)

\begin{tabular}{|c|c|c|c|c|c|}
\hline & /prosba/ & 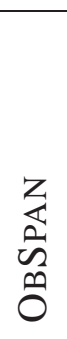 & 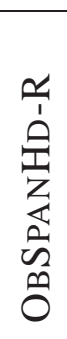 & 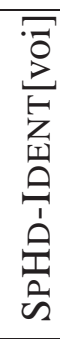 & $\begin{array}{l}\bar{\sigma} \\
\bar{z} \\
\bar{z} \\
\vec{y} \\
\overrightarrow{0}\end{array}$ \\
\hline a. & 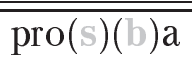 & *!! & & & \\
\hline b. 喓 & pro(zb)a & & & & $*$ \\
\hline c. & pro(sp)a & & $* !$ & & $*$ \\
\hline d. & pro(sp)a & & & $* !$ & $*$ \\
\hline
\end{tabular}

\begin{tabular}{|c|c|c|c|c|c|}
\hline & /predka/ & 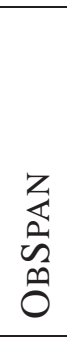 & 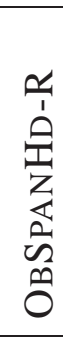 & 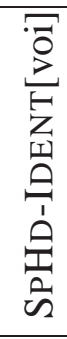 & 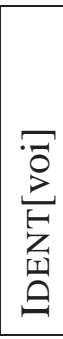 \\
\hline a. & $\overline{\text { pre(d)(k)a }}$ & $*$ *! & & & \\
\hline b. 棵 & pre(tk)a & & & & $*$ \\
\hline c. & $\operatorname{pre}(\mathrm{g}) \mathrm{a}$ & & $* !$ & & $*$ \\
\hline d. & pre $(d g) a$ & & & $* !$ & $*$ \\
\hline
\end{tabular}

a neighbouring obstruent, regardless of whether it is the first or the second member of the cluster. Thus, $\check{r}$ is unique in undergoing both progressive and regressive assimilation. Examples of both patterns are provided in (7). ${ }^{5}$

\begin{tabular}{|c|c|c|}
\hline ziist & 'to see (poet)' & progressive \\
\hline k & 'clamour NOM.SG' & \\
\hline $\begin{array}{l}\text { rve } \\
\text { moisski: }\end{array}$ & $\begin{array}{l}\text { 'cry 3SG' } \\
\text { 'maritime M' }\end{array}$ & regressive \\
\hline
\end{tabular}

Nothing we have said so far is able to account for this behaviour. As the tableau in (8) makes clear, $\check{r}$ is predicted to participate in nothing more than regressive assimilation.

\section{Biaspectual Phonology}

Biaspectual Phonology (BP) resurrects the idea that phonology mediates between stored lexical and discrete phonetic representations. In Process Morphophonemics the input was equated with the stored lexical representation. A central tenet of OT, however, is the Richness of the Base, according to which there are no (languageparticular) restrictions on input forms: The burden of description falls on the outputoriented constraints. In Biaspectual Phonology, the input from the rich base is mapped onto a unique output representation, $\pi$, just as in Classical OT. In BP, however, $\pi$ is interpreted by two extragrammatical systems, a phonetic interpretation system

\footnotetext{
${ }^{5}$ We will distinguish obstruent and sonorant versions of $\check{r}$ in transcription as follows: $/ \mathrm{r} /=$ obstruent post-alveolar trill; $/ \mathrm{f} /$ = sonorant post-alveolar trill.
} 
Sylvia Blaho and Patrik Bye

(8) Progressive devoicing - incorrect prediction for $\check{r}$

\begin{tabular}{|c|c|c|c|c|c|}
\hline & /krik/ & \begin{tabular}{l}
$z$ \\
\multirow{2}{a}{} \\
$\sim$ \\
0 \\
0
\end{tabular} & 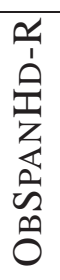 & 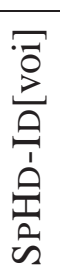 & 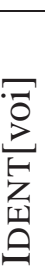 \\
\hline a. & 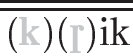 & $* !$ & & & \\
\hline b. & $(\mathrm{g}) \mathrm{ik}$ & & & & $*$ \\
\hline c. & $(\mathrm{k} i) \mathrm{ik}$ & & $* !$ & & $*$ \\
\hline d. $:$ & $\left(\mathrm{k}^{\circ}\right) \mathrm{ik}$ & & & $i^{* !}$ & $*$ \\
\hline
\end{tabular}

$\Phi$ and a lexical recognition system $\Lambda$. The phonological grammar may in principle 'show' these systems different aspects of the output representation, making $\pi$ literally 'two-faced'. In a biaspectual output representation, every node, feature and association line is flagged by GEN for its visibility to $\Lambda$ and $\Phi$. For an input node /X/, there are four logically possible output descriptions, shown in (9). Input representations are not flagged in this way.

(9) $\quad \mathrm{X}_{\phi}^{\lambda} \quad \mathrm{X}$ is visible to both $\Phi$ and $\Lambda$

$\mathrm{X}_{\phi} \quad \mathrm{X}$ is visible to $\Phi$ only

$\mathrm{X}^{\lambda} \quad \mathrm{X}$ is visible to $\Lambda$ only

$\mathrm{X} \quad \mathrm{X}$ is invisible $(=\emptyset)$

It is necessary to modify the definitions of constraints in the light of this conception of the phonological representation. Faithfulness constraints require visibility of input material to $\Lambda$. Markedness constraints require the invisibility of input material to one or the other system, $\Lambda$ or $\Phi$. In addition, we introduce a third type of constraint, TRANSPARENCY, which require matching (in)visibility for $\Lambda$ and $\Phi$.

We'll address markedness first. Markedness constraints penalize visibility of phonological structure to one of the two interpretative systems rather than phonological structure per se. (10-a) Returns a violation mark for every $\mathrm{X}_{\phi}$ (including $\mathrm{X}_{\phi}^{\lambda}$ ), whereas (10-b) returns a mark for every $\mathrm{X}^{\lambda}$ (including $\mathrm{X}_{\phi}^{\lambda}$ ). (10-b) suppresses the visibility of allophonic variation to $\Lambda$ and may thus be compared to *SPEC (Prince and Smolensky 1993).

Faithfulness constraints require visibility of input information to $\Lambda$ only. Given an input $/ \alpha \mathrm{F} /$, the IDENT constraint in (12) below returns violation marks for every $[-\alpha \mathrm{F}]^{\lambda}$, but not for $[-\alpha \mathrm{F}]_{\phi}$. 
(10)
a. $* \mathrm{X}_{\phi}$
$\mathrm{X}$ is invisible to $\Phi$.
b. $* \mathrm{X}^{\lambda}$
$\mathrm{X}$ is invisible to $\Lambda$.

(11)

Evaluation

\begin{tabular}{|ll||cc|}
\hline & /X/ & $* \mathrm{X}_{\phi}$ & $* \mathrm{X}^{\lambda}$ \\
\hline \hline a. & $\mathrm{X}_{\phi}^{\lambda}$ & $*$ & $*$ \\
\hline b. & $\mathrm{X}^{\lambda}$ & & $*$ \\
\hline c. & $\mathrm{X}_{\phi}$ & $*$ & \\
\hline d. & $\mathrm{X}=\emptyset$ & & \\
\hline
\end{tabular}

(12) $\operatorname{IDENT}[\alpha \mathrm{F}]^{\lambda}$ : If $\mathrm{X}$ is $[\alpha \mathrm{F}]$ in the input, the output correspondent of $\mathrm{X}$ is visible to $\Lambda$ as $[\alpha \mathrm{F}]$.

There is no empirical evidence for a comparable constraint requiring visibility of input material to $\Phi$, and so we will not assume its existence in CON.

Evaluation of $\operatorname{IDENT}[\alpha \mathrm{F}]^{\lambda}$

\begin{tabular}{|ll||c|}
\hline & $/ \alpha \mathrm{F} /$ & IDENT[F] \\
\hline \hline a. & {$[\alpha \mathrm{F}]_{\phi}^{\lambda}$} & \\
\hline b. & {$[\alpha \mathrm{F}]^{\lambda},[-\alpha \mathrm{F}]_{\phi}$} & \\
\hline c. & {$[-\alpha \mathrm{F}]^{\lambda},[\alpha \mathrm{F}]_{\phi}$} & $*$ \\
\hline d. & {$[-\alpha \mathrm{F}]_{\phi}^{\lambda}$} & $*$ \\
\hline
\end{tabular}

Candidate (b) represents the kind of situation we find in cases of cryptosegmentalism. Cryptosegments bear apparently conflicting specifications for some feature $[\mathrm{F}]$. However, the conflict is only apparent, since the $[+\mathrm{F}]$ and $[-\mathrm{F}]$ specifications are visible to different systems. In the case of a cryptosonorant, only the [+son] specification is visible to $\Lambda$, and only the [-son] specification is visible to $\Phi$.

The third type of constraint we need is TRANSPARENCY. The biconditional constraint in (14) returns a violation mark for every candidate in which $\Lambda$ and $\Phi$ see different aspects of $[\mathrm{F}]$.

(14) TRAns[F]: Segment $x$ is visible to $\Lambda$ as $[\alpha \mathrm{F}]$ iff it is visible to $\Phi$ as $[\alpha \mathrm{F}]$.

(15) Evaluation of TRANS[F]

\begin{tabular}{|ll||c|}
\hline \multicolumn{2}{|c||}{$/ \alpha \mathrm{F} /$} & TRANS[F] \\
\hline \hline a. & {$[\alpha \mathrm{F}]_{\phi}^{\lambda}$} & \\
\hline b. & {$[\alpha \mathrm{F}]^{\lambda},[-\alpha \mathrm{F}]_{\phi}$} & $*$ \\
\hline c. & {$[-\alpha \mathrm{F}]^{\lambda},[\alpha \mathrm{F}]_{\phi}$} & $*$ \\
\hline d. & {$[-\alpha \mathrm{F}]_{\phi}^{\lambda}$} & \\
\hline
\end{tabular}




\section{Sylvia Blaho and Patrik Bye}

The interaction of $\mathrm{MARK}_{\phi}, \mathrm{FAITH}^{\lambda}$ and TRANS generates the typology shown in (16). Of the four logically possible parses of input $/ \alpha \mathrm{F} /$ shown in (13) and (15), only three are optimal on some ranking of the constraints. The faithful and transparent candidate (a) is selected as winner whenever FAITH ${ }^{\lambda}$ and TRANS outrank $\operatorname{MARK}_{\phi}$. The unfaithful but transparent candidate (d) is optimal whenever MARK and TRANS outrank FAITH ${ }^{\lambda}$. The cryptosegment candidate (d), with covert preservation of $[\alpha \mathrm{F}]$, will prevail if $\mathrm{FAITH}^{\lambda}$ and $\mathrm{MARK}_{\phi}$ take priority over TRANS. Candidate (c) is harmonically bounded, since it is neither faithful nor transparent. Note that introducing $\mathrm{MARK}^{\lambda}$ into the typology will still leave (c) harmonically bounded by (d).

Typology

a. Full preservation: $/ \alpha \mathrm{F} / \rightarrow[\alpha \mathrm{F}]_{\phi}^{\lambda}$

\begin{tabular}{|ll||cc|c|}
\hline & $/ \alpha \mathrm{F} /$ & TRANS[F] & IDENT $[\mathrm{F}]^{\lambda}$ & $*[\alpha \mathrm{F}]_{\phi}$ \\
\hline \hline a. & {$[\alpha \mathrm{F}]_{\phi}^{\lambda}$} & & & $*$ \\
\hline b. & {$[\alpha \mathrm{F}]^{\lambda},[-\alpha \mathrm{F}]_{\phi}$} & $*$ & & \\
\hline c. & {$[-\alpha \mathrm{F}]^{\lambda},[\alpha \mathrm{F}]_{\phi}$} & $*$ & $*$ & $*$ \\
\hline d. & {$[-\alpha \mathrm{F}]_{\phi}^{\lambda}$} & & $*$ & \\
\hline
\end{tabular}

b. Full change: $/ \alpha \mathrm{F} / \rightarrow[-\alpha \mathrm{F}]_{\phi}^{\lambda}$

\begin{tabular}{|ll||cc|c|}
\hline & $/ \alpha \mathrm{F} /$ & TRANS $[\mathrm{F}]$ & $*[\alpha \mathrm{F}]_{\phi}$ & ${\text { IDENT }[\mathrm{F}]^{\lambda}}$ \\
\hline \hline a. & {$[\alpha \mathrm{F}]_{\phi}^{\lambda}$} & & $*$ & \\
\hline b. & {$[\alpha \mathrm{F}]^{\lambda},[-\alpha \mathrm{F}]_{\phi}$} & $*$ & & \\
\hline c. & {$[-\alpha \mathrm{F}]^{\lambda},[\alpha \mathrm{F}]_{\phi}$} & $*$ & $*$ & $*$ \\
\hline d. & {$[-\alpha \mathrm{F}]_{\phi}^{\lambda}$} & & & $*$ \\
\hline
\end{tabular}

c. Covert preservation: $/ \alpha \mathrm{F} / \rightarrow[\alpha \mathrm{F}]^{\lambda},[-\alpha \mathrm{F}]_{\phi}$

\begin{tabular}{|ll||cc|c|}
\hline & $/ \alpha \mathrm{F} /$ & $*[\alpha \mathrm{F}]_{\phi}$ & ${\text { IDENT }[\mathrm{F}]^{\lambda}}$ & TRANS[F] \\
\hline \hline a. & {$[\alpha \mathrm{F}]_{\phi}^{\lambda}$} & $*$ & & \\
\hline b. & {$[\alpha \mathrm{F}]^{\lambda},[-\alpha \mathrm{F}]_{\phi}$} & & & $*$ \\
\hline c. & {$[-\alpha \mathrm{F}]^{\lambda},[\alpha \mathrm{F}]_{\phi}$} & $*$ & $*$ & $*$ \\
\hline d. & {$[-\alpha \mathrm{F}]_{\phi}^{\lambda}$} & & $*$ & \\
\hline
\end{tabular}

OT with biaspectual output representations is thus fully parallel, with GEN returning for each input a unique output form that contains any information necessary to deal with opaque generalisations. ${ }^{6}$ In opaque cases, constraints must be able to make

\footnotetext{
${ }^{6}$ In this way it is similar in spirit to some other proposals in the literature, such as Turbidity Theory (Goldrick 2000) and Coloured Containment (Oostendorp 2005).
} 


\section{Cryptosonorants in Biaspectual Phonology}

reference to any covert information. The next section will provide an example of this.

\section{Biaspectual Analysis of Czech $\check{r}$}

The core assumption in our analysis is that $\check{r}$ is visible to $\Lambda$ as a sonorant but to $\Phi$ as an obstruent. Both the obstruent and sonorant versions of $\check{r}$ are plausible inputs. In keeping with the Richness of the Base, both $/ \mathrm{f} /$ and $/ \mathrm{r} /$ must be shown to map onto the right output as well as behaving phonologically in the right way. We assume markedness constraints in (17) and (18).

$$
\begin{aligned}
& { }_{\mathrm{r}^{\lambda}}^{\lambda} \text { : Post-alveolar trills are not visible to } \Lambda \text { as }[-\mathrm{son}] \text {. } \\
& { }_{\mathrm{f}_{\phi}} \text { : Post-alveolar trills are not visible to } \Phi \text { as }[+ \text { son }] \text {. }
\end{aligned}
$$

The constraints in (19)-(22) are relativised versions of (3) and (4) for visibility to $\Lambda$ or $\Phi$.

(19) $\operatorname{OBSPAN}^{\lambda}$ : A sequence of consecutive segments visible to $\Lambda$ as [-son] form a span on the [voice] tier.

(20) $\mathrm{OBSPAN}_{\phi}$ : A sequence of consecutive segments visible to $\Phi$ as [-son] form a span on the [voice] tier.

(21) ОвSPANHD- $\mathrm{R}^{\lambda}$ : Every span visible to $\Lambda$ is right-headed.

(22) ОвSPANHD- $\mathrm{R}_{\phi}$ : Every span visible to $\Phi$ is right-headed.

Instead of (5), we need a $\Lambda$-relativised identity constraint (23), as well as one requiring that span heads have matching specifications for voice on both $\Lambda$ and $\Phi$ (24).

(23) SPHD-IDENT[voi] ${ }^{\lambda}$ : For all $x, x$ is the head of a $\Lambda$-visible span, $x$ is faithful to its input specification for [voice] for $\Lambda$.

(24) $\operatorname{SPHD}^{\lambda}$-TRAns[voi]: For all $x, x$ is the head of a $\Lambda$-visible span, $x$ is visible to $\Lambda$ as [ $\alpha$ voice] iff it is visible to $\Phi$ as [ $\alpha$ voice].

The opaque progressive devoicing pattern of $/ \mathrm{r} /$ is shown in tableau (25). ${ }^{7}$ The faithful and transparent candidate (i.), in which $/ \mathrm{R} /$ projects as a sonorant to both $\Lambda$

\footnotetext{
${ }^{7}$ In our tableaux we use the following notation:

(...) $\Lambda$-visible span $\mathbf{X}$ Head of $\Lambda$-visible span only

[...] $\Phi$-visible span $\mathbb{X}$ Head of $\Phi$-visible span only

X Head of $\Lambda$ - \& $\Phi$-visible span
}

$\mathrm{R}_{\phi: \mathrm{I}}^{\lambda: \mathrm{f}}$ Segment visible to $\Lambda$ as $/ \mathrm{f} /$,
$\quad$ but to $\Phi$ as [iْ] 


\section{Sylvia Blaho and Patrik Bye}

and $\Phi$, is ruled out by the high-ranked markedness constraint ${ }^{*} \mathrm{~F}_{\phi}$ defined in (18), which forbids the pronunciation of $/ \mathrm{R} /$ as a sonorant. The other markedness constraint in (17), ${ }^{*} \mathrm{r}^{\lambda}$, excludes candidates (d.), (e.), (g.), (h.) and (j.), because they fail to render $/ \mathrm{R} /$ visible as [+sonorant] to $\Lambda$. OBSPAN ${ }_{\phi}$ is violated by (c.), since the two obstruents do not form a voice span for $\Phi$ (i.e., the cluster differs in voicing). Candidate (b.) violates SPHD-IDENT[voi] ${ }^{\lambda}$ because the velar stop, the head of the $\Lambda$ span, is not faithful to its input specification for [voice]. Finally, candidate (f.) is ruled out by $\mathrm{SPHD}^{\lambda}$-TRANS[voi] because the velar stop does not have matching [voice] specifications for $\Lambda$ and $\Phi$. The winning candidate contains a voiceless velar stop followed by a post-alveolar trill that is visible to $\Lambda$ as a sonorant but to $\Phi$ as a voiceless obstruent, thus producing an obstruent cluster that agrees in voicing but its voicing specification is determined by its leftmost member.

Opaque progressive devoicing of $/ \mathrm{r} /$ - sonorant input

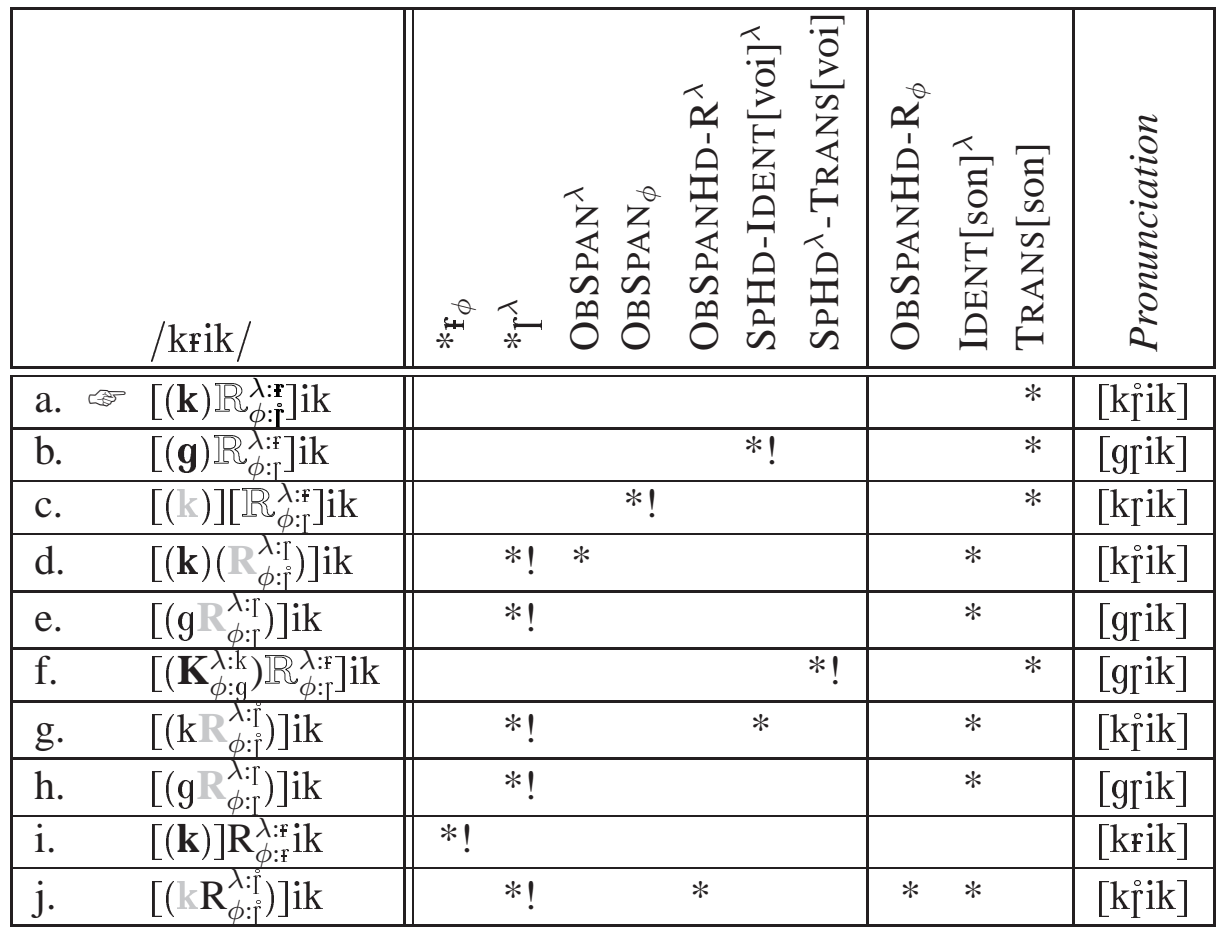

By the principle of the Richness of the Base, we must also address how the grammar deals with an obstruent input, $/ \mathrm{\gamma} /$. Due to highly ranked (18), this is forced to project to $\Lambda$ as a sonorant. This is shown in tableau (26). Note that since the same candidates are presented in (25) and (26), the only violations in (26) that are different from 


\section{Cryptosonorants in Biaspectual Phonology}

(25) are those for IDENT[son] $]^{\lambda}$. However, this constraint is low-ranked, so it does not change the outcome of the evaluation. Hence, the proposed ranking produces the correct result regardless of the input.

Opaque progressive devoicing of $/ \mathrm{r} /$ - obstruent input

\begin{tabular}{|c|c|c|c|c|c|c|c|c|}
\hline & /krik/ & + & 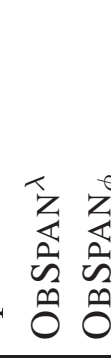 & 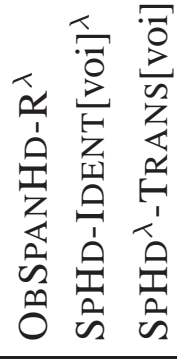 & 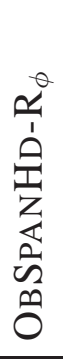 & 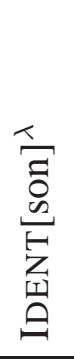 & 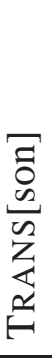 & 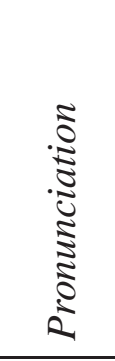 \\
\hline a. $\quad$ 吗 & {$\left[(\mathbf{k}) \mathbb{R}_{\phi:]^{\prime}}^{\lambda: ₹}\right] \mathrm{ik}$} & & & & & $*$ & $*$ & [kíik] \\
\hline b. & {$\left[(\mathbf{g}) \mathbb{R}_{\phi: \Gamma}^{\lambda: \mathrm{f}}\right] \mathrm{ik}$} & & & $* !$ & & $*$ & $*$ & [grik] \\
\hline c. & {$[(\mathbb{K})]\left[\mathbb{R}_{\phi: r}^{\lambda: ₹}\right] \mathrm{ik}$} & & $*$ & & & $*$ & $*$ & [krik] \\
\hline d. & {$\left[(\mathbf{k})\left(\mathbb{R}_{\phi: \tilde{r}}^{\lambda: r}\right)\right] \mathrm{ik}$} & $* !$ & $*$ & & & & & [krik] \\
\hline e. & {$\left[\left(g \mathbb{R}_{\phi: r}^{\lambda: r}\right)\right] \mathrm{ik}$} & $* !$ & & & & & & [grik] \\
\hline f. & {$\left[\left(\mathbf{K}_{\phi: g}^{\lambda: \mathrm{k}}\right) \mathbb{R}_{\phi: !}^{\lambda: \mathrm{r}}\right] \mathrm{ik}$} & & & $* !$ & & & $*$ & [grik] \\
\hline g. & {$\left[\left(\mathrm{kR}_{\phi: \mathrm{i}}^{\lambda: \mathrm{i}}\right)\right] \mathrm{ik}$} & $* !$ & & $*$ & & & & [k kijik] \\
\hline & {$\left[\left(g \mathbb{R}_{\phi: r}^{\lambda: r}\right)\right] \mathrm{ik}$} & $* !$ & & & & & & [grik] \\
\hline i. & {$[(\mathrm{k})] \mathrm{R}_{\phi: \mathrm{f}}^{\lambda: \mathrm{ik}}$} & $* !$ & & & & $*$ & & [kfik] \\
\hline j. & {$\left[\left(\mathbb{k} \mathrm{R}_{\phi: \mathfrak{i})}^{\lambda \cdot \hat{I}}\right)\right] \mathrm{ik}$} & $* !$ & & $*$ & $*$ & & & [kioik] \\
\hline
\end{tabular}

\section{1. $\quad \check{r}$ : The Transparent Regressive Pattern}

The canonical pattern of voicing assimilation in Czech is regressive irrespective whether source and trigger are separated by a word boundary or not. The behaviour of $\check{r}$ in this regard is different. When a word-initial $\check{r}$ is preceded by a voiceless obstruent, it can only trigger regressive voicing assimilation as shown in (27).

$$
\begin{aligned}
& \text { Regressive voicing assimilation across words with } T \\
& / \underline{\mathrm{s}} \text { retfi: } \rightarrow \text { [zretfi: }] \text { 'with a speech' } \\
& / \text { ma: } / / \quad \text { [ma:ziritst }] \text { 'you shall say' }
\end{aligned}
$$

Here, $\check{r}$ is behaving unambiguously as an obstruent. Whatever constraint requires this must take priority over $* \mathrm{r}^{\lambda}$ in (18). Although apparently covert, the behaviour of $\check{r}$ in this environment may be likened to the fortition of rhotics found in domain- 


\section{Sylvia Blaho and Patrik Bye}

initial position in some languages such as Spanish (Bakovic 1995). We capture the pattern with the constraint in (28).

(28) $*\left[W_{d} \mathrm{f}^{\lambda}\right.$ : In word-initial position, a post-alveolar trill is visible to $\Lambda$ as [-son].

The evaluation of the behaviour of word-initial $\check{r}$ is shown in tableau (29). Because $*\left[W d^{\mathrm{f}^{\lambda}}\right.$ outranks ${ }^{*} \mathrm{r}^{\lambda}$, the candidate with the covert sonorant (a.) is bested by candidate (e.), whose / $R /$ is transparently obstruent and triggers regressive voicing assimilation in the canonical way.

(29) Regressive voicing triggered by $/ \mathrm{r} /$ - sonorant input

\begin{tabular}{|c|c|c|c|c|c|c|c|}
\hline & /ma:S ristst/ & $\underset{*}{*}$ & 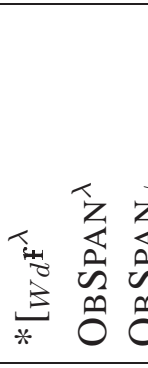 & 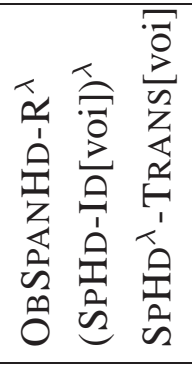 & ț & 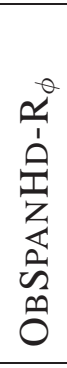 & 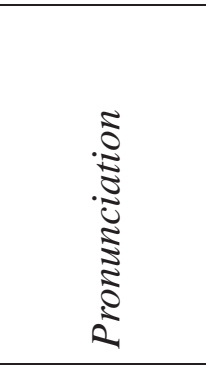 \\
\hline a. & $\overline{\mathrm{ma}}\left[\left(\int\right) \mathbb{R}_{\phi: \mathrm{j}}^{\lambda: ₹}\right] \mathrm{i}$ itst & & $* !$ & & & & [ma: $\int$ riitst] \\
\hline b. & $\mathrm{ma}:\left[(\mathbf{3}) \mathbb{R}_{\phi: 5}^{\lambda:}\right] \mathrm{i}$ itst & & $* !$ & $*$ & & & [ma:3 ri:tst] \\
\hline c. & ma: $\left[\left(\int\right)\right]\left[\mathbb{R}_{\phi: r}^{\lambda: p}\right]$ i:tst & & $* !$ & & & & [ma: $\int$ riitst] \\
\hline d. & $\operatorname{ma}\left[\left(\int\right)\left(\mathbb{R}_{\phi: \Gamma}^{\lambda: r}\right)\right] \mathrm{i} i t s t$ & & $* !$ & $*$ & $*$ & & [ma: $\int$ [iitst] \\
\hline e. & $\operatorname{ma}\left[\left(3 \mathbb{R}_{\phi: p}^{\lambda: r}\right)\right] \mathrm{i}: t s t$ & & & & $*$ & & [ma:3 [i:tst] \\
\hline f. & $\operatorname{ma}\left[\left(\int\right)\right]\left[\left(\mathbb{R}_{\phi: \mathrm{r}}^{\lambda: \mathrm{r}}\right)\right] \mathrm{i}: \mathrm{tst}$ & & $* !$ & & $*$ & & [ma: $\int$ [iitst] \\
\hline g. & $\operatorname{ma}\left[\left(\int \mathbb{R}_{\phi: \check{I}}^{\lambda: \dot{I}}\right)\right] \mathrm{i}: t s t$ & & & $* !$ & $*$ & & [ma: $\int$ [iitst] \\
\hline h. & $\operatorname{ma}:\left[\left(\int\right)\right] \mathrm{R}_{\phi: \mathrm{r}}^{\lambda: \mathrm{i}} \mathrm{i}$ tst & $* !$ & $*$ & & & & [ma:j fi:tst] \\
\hline i. & $\operatorname{ma}:\left[\left(\int \mathrm{R}_{\phi: \tilde{I}}^{\lambda: \tilde{I}}\right)\right] \mathrm{i}: \mathrm{tst}$ & & & $* !$ & $*$ & $*$ & 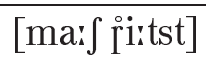 \\
\hline
\end{tabular}

\section{Comparison with Other Parallelist Approaches to Opacity}

Without going into the details of an analysis, we'd briefly like to highlight what we see as the main descriptive problems facing the best known approaches to opacity within parallelist OT, Sympathy Theory (McCarthy 1999) and Candidate Chains Theory (McCarthy 2005). Both fail to deal satisfactorily with cases in which some generalization is opacified by an allophonic process. In such cases, generating the right outcome (i.e. the right allophone and the right behaviour) crucially depends on inputting the 'wrong' allophone. The style of interaction between processes re- 


\section{Cryptosonorants in Biaspectual Phonology}

quired here is a Duke-of-York derivation, /A/ $\rightarrow B \rightarrow A$, which Sympathy Theory is designed to avoid. In the Czech case, Sympathy would require us to assume the input to $[\mathrm{r}]$ is its sonorant allophone $/ \mathrm{r} /$, since an input obstruent $/ \mathrm{r} /$ would be predicted to behave like an obstruent in assimilation. One possible way out is to map the problematic allophone $/ \mathrm{r} /$ onto something else, say $[\mathrm{r}]$, but this strategy seems psycholinguistically implausible. The problem is compounded in Candidate Chains Theory (CCT; McCarthy 2005), in which GEN can only generate candidates which are harmonically ascending chains of forms, making it impossible to map / $\mathrm{r} /$ to [r] via intermediate [r] Duke-of-York fashion. An input obstruent /r/ would always be compelled to behave like an obstruent in assimilation. Biaspectual Phonology is able to circumvent these problems since, as shown in the previous section, either of the inputs $/ \mathrm{f} /$ or $/ \mathrm{r} /$ must be rendered visible to $\Lambda$ as a sonorant, irrespective of how the same segment views at $\Phi$. In this way, BP is able to deal with opacity without raising the problems of input-sensitivity and the Richness of the Base. One additional aspect of the Czech data makes it impossible to model using Sympathy. Once we have a sympathetic selector which favours candidates preserving the sonorancy of an underlying / $/$ / ( $*$ IDENT[son]), we would get the wrong result whenever we have a word-initial / $\mathbf{f} /$ preceded by a voiceless obstruent. In this environment, $\check{r}$ behaves like any other obstruent in triggering regressive assimilation. The fact that sympathetic selectors behave as if undominated for the purposes of selecting the sympathetic candidate make it impossible to capture this schizophrenic behaviour.

\section{Conclusions}

Cryptosegments represent a special case of phonological opacity. Biaspectual Phonology (developed independently to deal with cases of complex rule interaction involving phonological opacity) provides the architecture necessary to derive cryptosegmental behaviour in fully parallel Optimality Theory.

\section{References}

Baković, Eric, 1995. Strong onsets and Spanish fortition. In Proceedings of SCIL 6. Cambridge, MA: MIT Department of Linguistics and Philosophy.

Bye, Patrik, 2005. Biaspectual representations in phonology and rule sandwiching. Ms., University of Troms $\varnothing$.

Dankovičová, Jana, 1999. Czech. In International Phonetic Association (ed.) The Handbook of the International Phonetic Association, 70-73. Cambridge: Cambridge University Press.

Goldrick, Matthew, 2000. Turbid Output Representations and the Unity of Opacity. In Proceedings of North East Linguistic Society (NELS) 30. 


\section{Sylvia Blaho and Patrik Bye}

Hall, Daniel Currie, 2003. Laryngeal fearure specifications in West Slavic languages. In Daniel Currie Hall (ed.) Toronto Working Papers in Linguistics. Special Issue on Contrast. Toronto: University of Toronto.

Kiparsky, Paul, 1973. Phonological representations. In O. Fujimura (ed.) Three Dimensions of Linguistic Theory, 1-136. Tokyo: TEC.

Ladefoged, Peter and Maddieson, Ian, 1996. The Sounds of the World's Languages. Oxford: Basil Blackwell.

McCarthy, John J., 1999. Sympathy and phonological opacity. Phonology 16:331399.

McCarthy, John J., 2004. Headed spans and autosegmental representations. Rutgers Optimality Archive 685. Available at http: / / roa.rutgers . edu.

McCarthy, John J., 2005. Optimal paradigms. In Laura Downing, Tracy A. Hall and Renate Raffelsiefen (eds.) Paradigms in Phonological Theory, 295-371. Oxford: Oxford University Press.

Oostendorp, Marc van, 2005. The theory of faithfulness. Ms., Meertens Instute, Amsterdam.

Postal, Paul M., 1968. Aspects of Phonological Theory. New York: Harper and Row.

Prince, Alan S. and Smolensky, Paul, 1993. Optimality Theory. Constraint Interaction in Generative Grammar. Technical Report \#2, Rutgers University Center for Cognitive Science.

Short, David, 1987. Czech and Slovak. In Bernard Comrie (ed.) The World's Major Languages, 367-390. Oxford: Oxford University Press.

Tuttle, Siri G., 2005. Cryptosonorant phonology in Galice Athabaskan. In Marc van Oostendorp and Jeroen van de Weijer (eds.) The Internal Organization of Phonological Segments, volume 77 of Studies in Generative Grammar. Berlin: Mouton de Gruyter.

Sylvia Blaho and Patrik Bye

Faculty of Humanities

University of Troms $\varnothing$

9037 Troms $\varnothing$

Norway

sylvia.blaho@hum.uit.no/patrik.bye@hum.uit.no 